\title{
The effect of motivational arousal on information processing in the convergent word identification task
}

\author{
PETER SUEDFELD AND NANCY GOELLER \\ RUTGERS-THE STATE UNIVERSITY, NEW BRUNSWICK, NEW JERSEY
}

\begin{abstract}
Motivational arousal led to improved performance on simple problems without affecting performance on complex problems. It also resulted in increased utilization of clues. Its effects seem more specific than those of high input, and may be explicable in terms of arousal theory.
\end{abstract}

A previous study (Suedfeld \& Hagen, 1966) showed that conceptually complex Ss were better than conceptually simple Ss (defined by the theory of Schroder, Driver, \& Streufert, 1967) at solving problems with a complex pattern of information distribution. Complex Ss also considered more of the available cues in making their decisions. A second experiment using the same problems (Suedfeld, 1966) demonstrated that when clues were presented at a faster rate (5 sec apart rather than 15), there was a decrease in solutions for complex problems, in recall of clues, and in utllization of remembered clues. It appeared that rapid presentation of clues had the effect of reducing the complexity of information processing. One possible reason for this was the sense of urgency in the high rate situation, which may have resulted in superoptimal cognitive arousal (see Blum, Geiwitz, \& Stewart, 1967). The current study tested the arousal hypothesis more directly, by varying Ss' motivation to perform well. Procedure

Thirty-two male college students were presented with the set of problems which we shall call the Convergent Word Identification Task (CWIT). As described previously (Suedfeld \& Hagen, 1966; Suedfeld, 1966), the CWIT consists of 14 series of 10 clues each. Every clue is a response to a Kent-Rosanoff Word Association stimulus; the $\mathbf{1 0}$ clues within any one series are responses to one common stimulus word as reported by Russell \& Jenkins (1954). Each set includes the five most popular responses $\left(R_{1-5}\right)$ and five idiosyncratic responses $\left(R_{1}\right)$. Seven sets present complex problems, in which $R_{1}$ through $R_{5}$ were given almost equally often by the standardization group, with an average probability of slightly over .10 (flat gradient group); the other seven sets (steep gradient group) are simpler since $R_{1}$ carries considerable information $(p=.55)$, with $R_{2}-R_{5}$ carrying most of the rest (total $p$ $=.30$ ). In this study, the clues were read orally to the Ss $10 \mathrm{sec}$ apart. Ss were instructed to guess the original stimulus word, then record all of the clues they remembered, then indicate which clues they actually had considered in making their guesses.

In the present study, two motivation conditions were used. The high incentive group (16 Ss) was told that the $S$ who solved the most problems correctly would receive $\$ 20$; the next three, their choice of $\$ 5$ or $2 \mathrm{~h}$ extra experimental participation credit in their introductory psychology course; and the next three, $2 \mathrm{~h}$ extra credit. The low incentive group was just asked to do its best.

\section{Resulis and Discussion}

ANOVA (McNemar, 1962, Case XV) for correct solutions yielded significant effects for complexity and interaction ( $F=5.74$ and $4.39, p<.05)$. The low incentive group was equally efficient at solving simple $\left(\overline{\mathrm{M}}_{\mathrm{s}}=\mathbf{2 . 0 6}\right)$ and complex problems $\left(\overline{\mathrm{M}}_{\mathrm{c}}=\mathbf{2 . 0 0}\right)$, but with high incentive simple problems showed a great improvement $\left(\bar{M}_{c}=2.06, \bar{M}_{s}=3.00, t=2.09, p<.05\right)$.

The total number of clues recalled was the same both in the low incentive $\left(\bar{M}_{S}=51.1, \vec{M}_{C}=51.1\right)$ and in the high incentive $\left(\bar{M}_{S}=54, \bar{M}_{c}=52.3\right)$ treatments.

The utilization of recalled clues was greater in solving the simple problems both in the high incentive group $\left(\overline{\mathrm{M}}_{\mathrm{s}}=84.4 \%, \overline{\mathrm{M}}_{\mathrm{c}}=78.6 \%, \mathrm{t}=3.11, \mathrm{p}<.01\right)$, and in the low incentive group $\left(\overline{\mathrm{M}}_{\mathrm{S}}=72.2 \%, \overline{\mathrm{M}}_{\mathrm{C}}=63.6 \%\right.$, $t=4.60, p<.001$ ). Further, the high incentive group used significantly more of the clues they recalled ( $F=17.1, p=.001 ; \bar{M}=81.5 \%$ vs $62.4 \%)$.

It appears that higher motivation was more specific in its effects than higher input rate; where the latter had caused a general performance decrement, the former had a beneficial effect on the solution of simple problems. This finding is compatible with theories such as Spence's (1956); under high arousal, dominant responses (which for the steep gradlent problems are more likely to be correct) become more dominant still. Why was there no accompanying decrement in complex solution? One possibllity is that the rewards were not sufficiently arousing for that phenomenon to occur; another, that the high probability of winning something (seven of the $16 \mathrm{Ss}$ would get a prize) reduced the motivational impact of the competition. It may be that with the flat gradient distribution there is no dominant response, whether correct or incorrect, and that therefore there is no differential reduction of response probability as a function of arousal.

The greater reported utilization of clues on simple problems is difficult to account for. It is certainly not very adaptive, and may help to explain the consistently worse performance of Ss on the complex 
sets. Since the $\mathrm{Ss}$ of course receive no information at all concerning problem complexity, the reason for their discrimination needs to be investigated. The increased use of clues under high incentive was contrary to our expectation that information processing would become simplified, although it may reflect impaired discrimination of clues which are usually considered irrelevant.

\section{References}

BLUM, G. S., GEIWITZ, P. J., \& STEWART, C. G. Cognitive arousal: the evolution of a model. J. Pers. soc. Psychol, 1967, 5, 138-151. McNEMAR, Q. Psychological statistics. (3rd ed.) New York: Wiley, 1962.
RUSSELL, W. A., \& JENKINS, J. J. The complete Minnesota norms for responses to 100 words from the Kent-Rosanoff Word Association Test. ONR Tech. Rep., No. 11, 1954.

SCHRODER, H. M., DRIVER, M. J., \& STREUFERT, S. Human information processing. New York: Holt, Rinehart, \& Winston, 1967. SPENCE, K. W. Behavior theory and conditioning. New Haven: Yale University Press, 1956.

SUEDFELD, $P$. Information processing: the effects of differential pattern complexity and input rate. Psychon. Sci, 1966, 6, 249-250.

SUEDFELD, P., \& HAGEN, R. L. Measurement of information complexity: I. Conceptual structure and information pattern as factors in information processing. J. Pers. soc. Psychol, 1966, 4, 233-236. Note

1. This research was financed by a grant from the Rutgers University Research Council to the senior author. 